\title{
Pensando em sistemas abertos: aprendizados, eficiência adaptativa e incertezas em Douglass North
}

Thinking about open systems: learning, adaptive efficiency and uncertainties in Douglass North

\author{
Guilherme de Queiroz-Stein ${ }^{(1,2)}$ \\ (1) University of Münster \\ (2) Universidade Federal do Rio Grande do Sul
}

\begin{abstract}
In the present paper, I propose a reflection on the relationship between the field of institutional studies and pluralism in Economic Sciences, exploring some of Douglass North's contributions. To this end, I discuss how the categories of learning and adaptive efficiency are mobilized to account for the relationships between institutional and economic change, incorporating the agents' intentionality. Still, the epistemological challenges of assuming ubiquitous uncertainty as a prerequisite for institutional economic analysis are discussed. The main contribution is to demonstrate how Douglass North's thinking approaches the characterization of economic systems as open systems, in the sense proposed by Sheila Dow in her concept of structured pluralism.
\end{abstract}

\section{Keywords}

open systems, institutions, uncertainty, learning, adaptive efficiency.

JEL Codes B25, B4, B52.

\section{Resumo}

Neste artigo, é proposta uma reflexão a respeito da relação entre o campo de estudos institucionalista e o pluralismo em Ciências Econômicas, explorando algumas das contribuições de Douglass North. Para tanto, discute-se como as categorias de aprendizado e eficiência adaptativa são mobilizadas para dar conta das relações entre mudança institucional e econômica, incorporando a intencionalidade dos agentes. Ainda, são debatidos os desafios epistemológicos de assumir a incerteza ubiqua como pressuposto da análise econômica institucional. Considera-se que a principal contribuição deste trabalho é demonstrar de que forma o pensamento de Douglass North se aproxima da caracterização dos sistemas econômicos enquanto sistemas abertos, no sentido proposto por Sheila Dow em seu conceito de pluralismo estruturado.

\section{Palavras-chave}

sistemas abertos, instituições, incerteza, aprendizados, eficiência adaptativa.

Códigos JEL B25, B4, B52. 


\section{Introdução}

Nas últimas décadas ganha força o argumento de que as Ciências Econômicas têm passado por transformações significativas na forma como produzem conhecimento, de modo que o neoclassicismo teria perdido exclusividade enquanto matriz teórica que caracteriza o mainstream da área (Colander et al., 2004; Dequech, 2007). Entre os economistas é fortalecida a percepção de que, historicamente, essa ciência se desenvolveu em torno de um ambiente político e epistemológico plural, marcado pela diversidade teórica e metodológica, bem como pela disputa e pela controversa. Assim, o pluralismo seria um fator de potência quando se trata da produção de conhecimento sobre sistemas econômicos (Angeli, 2014; Bianchi, 1992; Fullbrook, 2003; Paula et al., 2003). Nesse contexto de produção científica, o campo da Economia Institucional tem sido apontado com um espaço propício para uma abertura metodológica e para a convergência teórica, desenvolvendo assim uma epistemologia plural e favorecendo o diálogo interdisciplinar (Campos, 2016; Conceição, 2002; Hodgson, 1999; Queiroz-Stein, 2018; Williamson, 2000).

Neste artigo, problematiza-se em que medida são verificadas essas transformações no mainstream e de que forma a Economia Institucional pode ser vista como um terreno fértil ao pluralismo. ${ }^{1}$ Pretende-se contribuir com essa discussão analisando a obra de Douglass North, especialmente em sua fase mais madura, manifesta na obra Understanding the process of economic change (2005). Assim, objetiva-se demonstrar que nela temos um exemplo importante, representativo e significativo de como os economistas institucionais tendem a pensar seu objeto como um sistema aberto, sendo essa a condição para se construir um campo científico que avança em torno do pensamento plural.

$\mathrm{Na}$ literatura brasileira, é crescente o interesse pelas ideias de North, encontrando-se trabalhos que tratam da relação entre Estado e economia (Fiani, 2003), contribuições para a teoria do desenvolvimento e do crescimento econômico (Campos, 2016; Lopes, 2013) e incorporação do concei-

1 Tradicionalmente, o campo da Economia Institucional é conformado por diversas formas de pensar o mundo econômico e, geralmente, a obra de Douglass North é classificada como pertencente à chamada Nova Economia Institucional. Contudo, considera-se que existem possibilidades pouco exploradas de interlocução e aproximação conceitual entre as distintas vertentes do pensamento econômico. Por essa razão, adota-se o termo mais abrangente de Economia Institucional. 
to de cultura na análise institucional (Azevedo, 2015; Costa, 2019). Contudo, é reduzido o número de estudos sobre aspectos epistemológicos e metodológicos, entre os quais destacam-se os artigos de Toyoshima (1999) e Gala (2003). Considera-se que o presente artigo pode contribuir para sanar essa lacuna, especialmente por focar-se em um período mais recente e maduro de sua teorização, explorando características de seu pensamento após ter ganho o Prêmio Nobel.

Para realizar a análise, seguimos os preceitos metodológicos do pluralismo crítico de Caldwell (1994) que recomendam a reconstrução racional das escolas econômicas, observando sua lógica interna e seus limites analíticos, a partir de determinado foco específico. O ponto de vista aqui assumido para analisar o trabalho de North é o da ontologia dos sistemas

abertos. Dessa maneira, adota-se a proposição de Sheila Dow e Victoria Chick, segundo a qual o pluralismo deve ser epistemologicamente fundamentado em uma ontologia dos sistemas abertos (Chick, 2004; Chick; Dow, 2005; Dow, 2004).

Assim, além da introdução, este trabalho conta com mais três partes. Na primeira, são apresentados os pressupostos metodológicos e as escolhas que guiam a análise, partindo dos conceitos de pluralismo crítico e de pluralismo estruturado. Na sequência, a obra escolhida é analisada procurando identificar em que medida ela se desenvolve concebendo os sistemas econômicos como um sistema aberto. Por fim, são apresentadas as considerações finais.

\section{Delineando uma metodologia pluralista}

A partir dos debates a respeito do anarquismo metodológico inaugurado por Feyerabend (1977), Bruce Caldwell (1994) propôs o conceito de pluralismo crítico para delinear o estudo de como as diferentes escolas do pensamento econômico desenvolvem concepções próprias sobre como investigar determinados fenômenos e produzir conhecimento. Dessa maneira, Caldwell sugeriu ao campo de estudos metodológicos não a busca de um método científico universal, mas o dever de compreender a essência das diversas perspectivas analíticas, adentrando suas formas de ver o mundo.

Para tanto, a primeira tarefa é a reconstrução racional do conteúdo metodológico da escola analisada. Isso deve ser feito deixando de lado pro- 
jeções metodológicas normativas, em prol de conhecer descritivamente a metodologia efetivamente mobilizada pelos economistas. Em seguida, o estudo deve identificar as forças e limitações da abordagem estudada, analisando-a criticamente. $\bigcirc$ resultado dessa análise, por sua vez, almeja possibilitar um diálogo mais fluído entre economistas de diferentes perspectivas, engendrando uma compreensão mútua profunda, bem como um diálogo crítico em que a teoria alvo de discussão é entendida em seus próprios termos. Para tal tarefa ser levada a cabo, é fundamental explicitar o ponto de vista a partir do qual essa reconstrução crítica será realizada. Esse ponto de vista funciona como um referencial-base para se avaliarem os limites e as forças do conteúdo metodológico da escola analisada (Caldwell, 1994).

Assim, a reconstrução crítica do conteúdo metodológico da obra de Douglass North será feita tendo em vista o problema de compreender a relação entre pluralismo e institucionalismo. Para tanto, ancora-se a análise no conceito de pluralismo estruturado, a partir do qual Sheila Dow (2004) argumenta que o pluralismo pode ser ontologicamente fundamentado na existência de sistemas abertos, sobre os quais não é possível produzir um conhecimento totalizante e determinístico. Um elemento importante desse conceito é assumir que, por trás de toda teoria, existem pressupostos ontológicos, que dizem respeito ao funcionamento da realidade, e pressupostos epistemológicos, que se referem à forma de conhecimento apropriada para analisar a realidade. Assim, o sistema pode ser aberto em nível de realidade e/ou em nível de teoria. Para essas autoras, o grau de abertura de um sistema varia de acordo com o nível em que o sistema é dinâmico e permeável para trocas com o ambiente. Para dar conta dessas distinções, estabeleceram-se condições necessárias e/ou suficientes que possibilitam analisar as teorias e seus pressupostos ontológicos, classificando-os como sistemas abertos ou fechados (Tabela 1) (Chick; Dow, 2005).

Segundo as autoras, satisfazer qualquer uma das condições entre I e IV na Tabela 1 é suficiente para assumir que se trata de pressupostos ontológicos de um sistema aberto. Do mesmo modo, satisfazer qualquer uma das condições entre V e VII é suficiente para designar um sistema teórico aberto. Dificilmente se encontrará um sistema aberto que satisfaça todas essas condições, sendo que a variabilidade na satisfação dessas condições é que produz uma diversidade de sistemas, em termos de graus de abertura (Chick; Dow, 2005). 
Tabela 1 Condições para um sistema aberto

\section{Sistemas no Mundo Real}

I. 0 sistema não é atomístico. Possui pelo menos uma das seguintes características:

a. Dadas as interações, os resultados das ações não podem ser inferidos das ações individuais;

b. Os agentes e suas interações podem ser modificados, existindo, por exemplo, aprendizado;

II. Estrutura e agência são interdependentes;

III. As fronteiras que circunscrevem e, também, as circunscritas (subsistemas) são mutáveis, por pelo menos uma das razões a seguir:

a. As estruturas sociais podem evoluir;

b. As conexões entre as estruturas podem mudar;

c. As relações estrutura-agente podem mudar; Estruturas sociais identificáveis estão imersas (embedded) em estruturas sociais mais

IV. amplas; elas podem interagir mutuamente, dado que, em geral, as fronteiras dos sistemas sociais são parciais ou semipermeáveis.

\section{Sistemas em Nível Teórico}

\begin{tabular}{l|l}
\hline V. & A classificação das variáveis entre endógenas e exógenas podem não ser fixas ou exaustivas;
\end{tabular}

VI. Conexões e/ou fronteiras entre as estruturas podem ser imperfeitamente conhecidas ou podem mudar;

Podem existir variáveis e/ou relações importantes que estão omitidas, e os seus efeitos no

VII. sistema podem ser incertos; há conhecimento imperfeito sobre as relações entre as variáveis; ainda, essas relações podem não ser estáveis.

Fonte: Traduzido e adaptado de Chick e Dow (2005, p. 366).

À luz dessas proposições, a análise da obra de Douglass North (2005) será dividida em duas partes. Na primeira serão identificados os pressupostos ontológicos que regem suas construções teóricas, observando se o autor percebe a realidade como um sistema aberto e qual o nível de abertura desse sistema, a partir das condições I-IV da Tabela 1. Em seguida, analisar-se-á sua construção teórica, discutindo se seu sistema é aberto ou fechado, seguindo as condições de $\mathrm{V}$ a VII.

A escolha do autor e da obra em análise se deve às seguintes razões. Primeiro, pela importância de North, que, como já foi referido, ganhou o Prêmio Nobel em 1993. Sua influência nas Ciências Econômicas e demais Ciências Sociais é difícil de ser mensurada, mas é suficiente mencionar que revolucionou pelo menos três áreas de estudo: a História Econômica, a Economia Institucional e as Teorias sobre Crescimento Econômico. Em grande medida, a profundidade de sua obra tinha por origem sua capacidade de avançar com questões, geralmente deixadas de lado por grande 
parte daqueles que tentavam entender os determinantes das performances econômicas (Wallis, 2016). Assim, é possível dizer que Douglass North incorporava em seu próprio trabalho uma perspectiva inovadora e plural.

Disso advém a segunda justificativa; a obra desse autor passa por mudanças ao longo do tempo que podem ser vistas em si mesmas como expressões das transformações que o mainstream econômico passou nas últimas décadas. Pode-se afirmar que até o início da década de 1990, mesmo quando se distanciava da teoria econômica ortodoxa, North não assumia uma postura de oposição crítica. Sua atitude era de postular a complementaridade do seu trabalho com aquele que havia sido desenvolvido pelos economistas ortodoxos (Gala, 2003).

Entretanto, no livro que aqui será objeto de análise, sua crítica é forte e direta. O método de teorização neoclássica, pautado pela elegância formal dos modelos, deixa de ser um ideal. Sua superação, inclusive, seria condição para elevar a utilidade da teoria social em dar conta dos problemas humanos. Afirma o autor:

The economic paradigm - neo-classical theory - was not created to explain the process of economic change. We live in an uncertain and ever changing world that is continually evolving in new and novel ways. Standard theories are of little help in this context. Attempting to understand economic, political, and social change (and one cannot grasp change in only one without the others) requires a fundamental recasting of the way we think. Can we develop a dynamic theory of change comparable in elegance to general equilibrium theory? The answer is probably not. But if we can achieve an understanding of the underlying process of change then we can develop somewhat more limited hypotheses about change that can enormously improve the usefulness of social science theory in confronting human problems (North, 2005, p. vii).

Em seus trabalhos mais recentes, pressupostos que fogem ao neoclassicismo ganham ainda mais centralidade, como a incerteza em um mundo não ergódigo e a racionalidade limitada. Também, destaca-se o caráter metodológico histórico-indutivo de sua obra, incorporando fatores psicossociais que expressam não só as transformações pelas quais passa o mainstream, mas a possibilidade de estabelecer um espaço de diálogo aberto e plural em torno da linguagem institucionalista.

Por fim, vale ressaltar que o principal motivo para a escolha de focar a análise no livro Understanding the process of economic change (North, 2005) diz respeito ao conceito de eficiência adaptativa. Em sua obra de 1990 - Institutions, institutional change and economic performance - o autor discute brevemente esse conceito, sem aprofundá-lo, associando a eficiência adaptativa a processos de aprendizados do tipo learning by doing e ao desenvol- 
vimento de conhecimentos tácitos, fruto de erros e acertos em diferentes tentativas de solucionar problemas societais (North, 1990, p. 73-82). Não há uma discussão mais substancial a respeito de como esses aprendizados são compartilhados pelos agentes econômicos e transformados em estoques de conhecimentos pelas sociedades. Consideramos que a obra de 2005 merece destaque justamente por suprir essa lacuna. Para tanto, North aprofunda a discussão dos mecanismos pelos quais esses processos ocorrem, buscando fundamentos explicativos nas Ciências Cognitivas, os quais serão discutidos a seguir.

\section{Sistemas abertos e a compreensão da mudança econômica}

Focando no livro Understanding the process of economic change, nesta seção discute-se como Douglass North concebe os sistemas econômicos como não atomísticos, caracterizados pela interdependência entre agência e estrutura, utilizando os conceitos de instituição, aprendizado e eficiência adaptativa. Em seguida, é abordada a relação entre mudança institucional e mudança econômica, considerando que as fronteiras do sistema econômico são permeáveis e mutáveis, estando as estruturas imersas em outras estruturas socioeconômicas. Em seguida, apresentam-se as implicações epistemológicas da análise de sistemas abertos em relação a três critérios: a classificação das variáveis entre endógenas e exógenas; a natureza mutável ou imperfeitamente conhecida das conexões e das fronteiras dos sistemas; a incerteza que permeia o sistema e a imperfeição do conhecimento produzido. Uma vez feita essa reconstrução da perspectiva de North, discutem-se alguns limites críticos em sua proposta.

\subsection{Instituições, aprendizados e eficiência adaptativa}

O ponto de partida de North é a crítica à teoria neoclássica, afirmando a dificuldade dessa teoria em explicar a mudança econômica, pois não incorpora a intencionalidade dos agentes. A mudança institucional, que implica mudanças econômicas, geralmente é resultado de ação intencional dos agentes, fruto de uma leitura sobre a realidade, tendo em vista determina- 
do fim. North enfatiza a importância de compreender como os humanos fazem escolhas e, para essa compreensão ser consistente, não se poderia recorrer a argumentos reducionistas:

The social sciences do not have anything comparable to genes, protons, neutrons, elements to build upon. The whole structure that makes up the foundation of human interaction is a construct of the human mind and has evolved over time in an incremental process; the culture of a society is the cumulative aggregate of the surviving beliefs and institutions (North, 2005, p. 83).

O pressuposto de racionalidade substantiva, em sua visão, só funcionaria em mercados competitivos, que possuíssem preços como parâmetros e quantidades como variáveis, em que os retornos das decisões tomadas (feedbacks) fossem praticamente instantâneos. Pela raridade dessas condições, esse pressuposto seria de baixa utilidade para explicar a maior parte dos fenômenos sociais. Para North, os mercados operam em ambientes complexos, em que os preços são endógenos e os agentes interagem estrategicamente, permeados por uma incerteza ubíqua. Nesse cenário, para se compreender a intencionalidade e a tomada de decisões, as Ciências Econômicas precisam incorporar em suas explicações a compreensão do funcionamento dos processos cognitivos.

Dessa forma, deve-se perceber a relação existente entre crenças, escolhas e mudanças institucionais. A chave para se compreender essas relações está nos processos evolucionários de aprendizado. Para dar conta desses processos, North busca apoio nas Ciências Cognitivas, assumindo o que se convencionou chamar de modelo conexionista (connectionist models), segundo o qual nosso cérebro e nossa mente funcionam por processos de seleção somática. Isso significa que a nossa cognição opera pelo aprendizado de padrões estatísticos sensoriais (pattern-based reasoning), e não por computação lógica simbólica.

Basicamente, esse modelo parte da ideia de que os processos mentais são uma propriedade emergente das complexas conexões de redes neurais. O armazenamento e a recuperação de informações, processadas nas nossas redes neurais, seguem uma lógica de sintetizar padrões informacionais percebidos pelos sentidos. Para tanto, o cérebro estabelece conexões entre eventos, identificando padrões. Esses padrões possibilitam interpretar novas experiências e são ajustados quando não se adaptam a essas. Dessa forma, estão sempre acumulando mutações e se adaptando de acordo com as diferentes experiências de relação entre a mente e o meio ambiente físico e sociocultural. 
Tais padrões, acumulados e processados em redes neurais são generalizados, produzindo conhecimento. $O$ conhecimento acumulado pode ser enriquecido através de processos de ordenação e reordenação das conexões, elevando o nível de abstração e a capacidade de processar informações. A essa dinâmica, Douglass North denomina descrição representacional (representational redescription) e, inspirado em Friedrich Hayek (1952), assume que o aprendizado é um processo de reorganização adaptativa de um sistema complexo e afirma que "Learning then is an incremental process filtered by the culture of a society which determines the perceived pay-offs" (North, 2005, p. 69). Assim, esse aprendizado nunca é somente um processo individual. Os indivíduos herdam padrões e conhecimentos das culturas em que estão imersos. É nesse sentido que se pode argumentar que a cultura é a chave para o entendimento de efeitos de dependência da trajetória (Costa, 2019).

Ao tomar decisões, os agentes estão inseridos em sistemas de crenças compartilhadas (ideologias, teorias, teologias, mitos etc.) que são determinantes para se compreender a intencionalidade dessas decisões. No nível individual, esse sistema de crenças conforma uma estrutura de categorias e classificações, pelas quais os agentes percebem o mundo e, a partir dessas percepções, decidem como agir. A essa estrutura, North denomina modelo mental, o qual é compartilhado em maior ou menor grau com outros indivíduos da mesma cultura ou do mesmo grupo social.

Os modelos mentais possibilitam aos indivíduos explicar e interpretar suas experiências de contato com o mundo físico e com o ambiente sociocultural que os circunscrevem. Por sua vez, ao entrar em contato com as novidades trazidas pela experiência, as percepções operam feedbacks que reforçam ou modificam os modelos mentais. Dessa forma, o aprendizado diz respeito a como cada indivíduo interpreta as informações com que se depara e a como essas informações levarão a reforços ou transformações nas categorias de classificação do mundo. Esses aprendizados são compartilhados, dado que muitos indivíduos podem se deparar com a mesma experiência.

Sob o ponto de vista dos sistemas abertos, o importante é que, em sua perspectiva, não se pode explicar o todo pelas partes. No mundo de Douglass North, os indivíduos não apenas interagem, mas também se modificam mutuamente, na medida em que compartilham de universos simbólicos e de experiências que implicam aprendizados coletivos. Esses, por sua 
vez, se refletem nas instituições e nas performances econômicas vividas por cada sociedade. Assim, se chega ao problema da interdependência entre agência e estrutura.

A relação entre estrutura e agência é um dos dualismos característicos do pensamento social contemporâneo (Corcuff, 2001), o qual procura demonstrar como as estruturas que conformam os sistemas sociais não possuem uma existência própria, com poder de determinar de modo absoluto as ações individuais. Pelo contrário, as estruturas são regras e recursos construídos historicamente pelas práticas de indivíduos e organizações. Segundo Giddens (2000), pode-se considerar que a interdependência entre estrutura e agência advém do fato de que a forma como se constituem as propriedades estruturais dos sistemas sociais depende dos agentes que utilizam recursivamente essas propriedades em suas ações e, ao fazer, reproduzem os sistemas sociais. Neste trabalho, considera-se que Douglass North avança nessa discussão, contribuindo com um arcabouço teórico próprio para equacionar a forma como essa interdependência se estabelece.

Há dois níveis em que o problema está colocado na obra de North. O primeiro é aquele que diz respeito à relação entre as instituições e a tomada de decisões individual. O segundo é o da relação entre o sistema de crenças compartilhadas e as crenças individuais. $O$ desafio teórico perseguido por North é o de integrar esses dois níveis e, a partir dessa integração, construir uma perspectiva que possibilite compreender os processos de mudança econômica.

No primeiro nível, o autor enfatiza a intencionalidade dos agentes na criação institucional e o papel das instituições em constranger a ação. Assume que instituições são os constrangimentos formais e informais que os seres humanos colocam a si mesmos: as regras do jogo. Basicamente, em sua visão, o homem cria instituições com o objetivo de reduzir a incerteza intrínseca ao mundo físico e sociocultural em que está inserido.

A inovação institucional é vista como um processo carregado de intencionalidade, fruto dos modelos mentais e dos sistemas de crenças de determinada sociedade. Isso significa que os atores possuem consciência dos processos históricos em que estão inseridos, de modo a realizar leituras positivas (como é) e normativas (como deve ser) sobre o mundo econômico, político e cultural. Essa leitura será a base para a construção de instituições, que implica a criação de uma matriz de constrangimentos sobre 
as escolhas futuras que serão feitas por empreendedores políticos e econômicos. Assim, a agência se expressa na intencionalidade, na consciência e na tomada de decisões, de tal modo que, no presente, a ação de criar é também um ato de restringir as possibilidades de ação futura.

Contudo, essa agência não opera no vazio. A criação institucional acontece em um universo de instituições preexistentes, que atuam em constranger e restringir as escolhas presentes. Assim, escolhas passadas criam uma matriz institucional que limita as escolhas presentes, delimitando também as possibilidades de inovação institucional. Ou seja, existe uma dependência da trajetória institucional pregressa (path dependence), de modo que a maior parte da mudança institucional é lenta e incremental.

Um segundo nível em que podemos perceber a interdependência entre agência e estrutura é o da relação entre o sistema de crenças compartilhadas e as crenças individuais. Os modelos mentais compartilhados por indivíduos conformam sistemas de crenças que são a herança cultural comum a determinado grupo ou sociedade. Por sua vez, a existência dessa herança cultural reduz a divergência entre os modelos mentais pelos quais os indivíduos interpretam e agem sobre o mundo. Dessa forma, a cultura possibilita uma transferência geracional de percepções mais ou menos unificadas, através da linguagem. É nela em que as categorias e os significados são estruturados, refletindo o acúmulo de experiências daquela sociedade.

Nesse sentido, é importante olhar para o plano da ação cotidiana e dos constrangimentos informais, que também são parte do arranjo institucional e podem vir a ser até mais determinantes para a performance econômica de determinada sociedade do que suas regras formais. Normas de honestidade, integridade, status, pertencimento, ostracismo são importantes fatores que operam na vida econômica, podendo reduzir ou aumentar os custos de transação conforme estão configurados. Assim, entender como as regras formais e as normas informais interagem é um elemento fundamental para se compreender as sociedades modernas. Nessas, as dinâmicas locais, regidas por constrangimentos informais, devem ser integradas por um arranjo de regras formalizadas, que possibilitem a realização de trocas entre pessoas e grupos sociais que não necessariamente comungam dos mesmos valores, de uma mesma religião, de uma mesma perspectiva política ou até de uma mesma linguagem.

Douglass North coloca essa questão inspirado em Hayek (1952), assumindo que a crescente divisão do trabalho em uma sociedade complexa é 
fundamentalmente uma crescente especialização de conhecimentos, fruto de experiências e aprendizados locais. Não é à toa que nessas sociedades os custos de transação são crescentes. Isso se deve à mente humana não estar naturalmente preparada para interagir em ambientes de tamanha complexidade. Sua racionalidade é limitada e, para mitigar essa limitação, é necessário criar artefatos externos que possibilitem a coordenação e a cooperação em um ambiente incerto. Reduzir custos transações significa criar arranjos institucionais que integrem os aprendizados locais, fazendo as trocas operarem com maior eficiência.

Um dos conceitos mais importantes propostos por North é o de estrutura de artefatos (artifactual structure), o qual é um primeiro passo rumo à integração dos dois níveis de interdependência entre estrutura e agência. A estrutura de artefatos é o conjunto de linguagens, crenças, instituições, organizações, ferramentas, instrumentos, códigos e tecnologias que uma sociedade criou e acumulou ao longo do tempo para dar conta da incerteza que permeia o ambiente físico e sociocultural. Mesmo que esses artefatos possuam uma realidade objetiva, material, fundamentalmente são processos mentais que dizem respeito a como agir e coordenar ações em um mundo incerto. Eles são a sedimentação de um conjunto de aprendizados compartilhados que estão disponíveis aos indivíduos. E, assim, emerge o papel cognitivo das instituições sociais em explicar a mudança econômica (North, 2005, p. 36).

Ao criar instituições para reduzir custos de transação, os agentes recorrem a esses aprendizados, que estão consolidados em seus sistemas de crenças compartilhados. A percepção dos problemas a serem enfrentados e dos caminhos a serem percorridos depende desses sistemas. Pode-se afirmar então que a grande inovação de North é perceber que os processos de evolução de sistemas de crenças e de sistemas institucionais andam juntos (Aoki, 2010). Dessa forma, a questão central da economia seria como explicar a diversidade de sistemas de crenças que evoluíram historicamente, e como isso se relaciona com a diversidade de estruturas institucionais e de performances econômicas encontradas no mundo. North propõe que quanto mais rica a estrutura de artefatos de uma sociedade maior sua capacidade de reduzir incertezas e, assim, maior a probabilidade de sucesso econômico ao longo do tempo.

Basicamente, a riqueza de uma estrutura de artefatos estaria em sua capacidade de se adaptar à novidade. Os ganhos da divisão do trabalho só 
são obtidos se a sociedade for capaz de construir instituições que façam os mercados de produtos e de fatores funcionarem de maneira eficiente, de modo que os agentes estejam competindo marginalmente. Porém, esse mundo é fruto de aprendizados dinâmicos que alteram as tecnologias empregadas, os custos informacionais e as decisões governamentais. Ou seja, alteram-se os parâmetros que regem o funcionamento daqueles mercados, de forma que não há garantias de que mercados hoje eficientes continuarão sendo amanhã. Para o sucesso econômico ocorrer é necessária alguma forma de eficiência dinâmica. Ou seja, é preciso ter capacidade de adaptar a estrutura institucional à novidade permanente que o mundo incerto nos lega. Dessa maneira, o determinante para a performance econômica seria a conquista de eficiência adaptativa.

North (1990, p. 79-82) propõe o conceito de eficiência adaptativa inspirado em diferentes linhagens do pensamento econômico, principalmente nos trabalhos de Hayek (1978), Nelson e Winter (1982) e Pelikan (1986). Enquanto o conceito de eficiência alocativa se refere à obtenção de um estado de alocação de recursos do tipo ótimo de Pareto em determinado momento do tempo, a eficiência adaptativa se refere às regras que moldam a evolução de uma economia ao longo do tempo, estabelecendo um conjunto de incentivos que direcionam processos de investimentos na formação de conhecimentos para a solução de problemas societais. Ou seja, é um fator dinâmico que opera ao longo do tempo em processos de aprendizados e aquisição de conhecimentos (tácitos ou codificados), bem como em processos criativos focados em inovação. Em sua formulação inicial, o próprio arranjo institucional seria um fator determinante para se obter ou não eficiência adaptativa:

We are far from knowing all the aspects of what makes for adaptive efficiency, but clearly the overall institutional structure plays the key role in the degree that the society and the economy will encourage the trials, experiments, and innovations that we can characterize as adaptively efficient. The incentives embedded in the institutional framework direct the process of learning by doing and the development of tacit knowledge that will lead individuals in decision-making processes to evolve systems gradually that are different from the ones that they had to begin with (North, 1990, p. 81).

Já em seu livro de 2005, North recorre às contribuições das Ciências Cognitivas para compreender processos de formação de crenças compartilhadas e a forma como interagem com dinâmicas de construção institucional. Desse modo, pode se considerar que as instituições se tornam endógenas ao modelo e, portanto, a eficiência adaptativa não é apenas determinada pela 
matriz institucional, mas é característica constituinte das regras que regem o funcionamento social e a performance econômica ao longo do tempo:

Adaptive efficiency entails an institutional structure that in the face of the ubiquitous uncertainties of a non-ergodic world will flexibly try various alternatives to deal with novel problems that continue to emerge over time. In turn this institutional structure entails a belief structure that will encourage and permit experimentation and equally will wipe out failures (North, 2005, p. 154).

Em síntese, Douglass North propõe uma nova forma de equacionar a interdependência entre estrutura e agência, o que é uma característica importante dos sistemas abertos. Não é possível reduzir o todo às partes, nem as partes são determinadas pelo todo. Essa interdependência pode ser percebida em dois níveis: instituições versus decisões; crenças compartilhadas versus crenças individuais. $O$ conceito de estrutura de artefatos parece ser fundamental em compreender o papel cognitivo das instituições, articulando os dois níveis. Isso implica uma análise institucional eminentemente dinâmica, focada nos processos de mudança institucional, enfatizando a forma como são delineados pela dependência da trajetória, incluindo o componente adaptativo que determina as performances econômicas. Ou seja, a capacidade das instituições de produzir soluções, avaliar seus resultados e rever seu direcionamento no caso de não serem adequadas aos problemas enfrentados. Na próxima seção, será discutida a forma como o autor utiliza esse arcabouço teórico para fundamentar a relação entre mudança institucional e mudança econômica.

\subsection{Mudanças institucionais e mudanças econômicas}

Na visão de Douglass North, a teoria neoclássica teria logrado sucesso em produzir explicações a respeito de como mercados operam em economias desenvolvidas. Contudo, teria pouco a dizer a respeito de como mercados e economias em geral evoluem. Isso se deve a três deficiências básicas dessa formulação teórica: a) partir da hipótese de um mundo sem fricções; b) basear-se em uma metodologia estática; c) não levar em conta a intencionalidade humana. Dessa forma, em sua proposta analítica, o autor procura avançar em pelo menos duas dessas deficiências: a intencionalidade dos agentes e a passagem do tempo. Para tanto, estabelece cinco proposições sobre a mudança institucional (North, 2005, p. 59-65). 
A primeira afirma que a contínua interação entre instituições e organizações, ${ }^{2}$ em um ambiente econômico de escassez e competição, é a chave para se compreender a mudança institucional. As instituições representam uma série de constrangimentos, que configuram o conjunto de oportunidades presentes em uma economia. Essa matriz de oportunidades será determinante para os tipos de organizações criadas. Por sua vez, essas organizações atuarão intencionalmente para alterar as regras formais e as normas informais ao perceberem que isso pode resultar em conjuntos novos de oportunidades que venham a favorecê-las.

Segundo: a escassez coloca os agentes em competição. $O$ arranjo institucional que regula essa competição condiciona os investimentos que os agentes e as organizações fazem na formação de conhecimentos e habilidades. Por sua vez, esses conhecimentos e habilidades alteram as percepções das oportunidades. Isso implica novas escolhas que, de forma incremental, modificam o ambiente institucional. Assim, a mudança institucional é endógena e quanto maior a competição maior será sua velocidade.

Terceiro: a forma como a matriz institucional condicionará os investimentos em conhecimentos e habilidades depende do modo como determina o conjunto de oportunidades percebidas pelos agentes (pay-offs). Esse conjunto de oportunidades implica diferentes resultados quanto à distribuição e ao produto, podendo oferecer mais incentivos para atividades distributivas ou para atividades produtivas. A escolha institucional, nesse sentido, é sempre uma escolha do quanto se priorizará redistribuir renda ou potencializar a produtividade. Historicamente, essa escolha foi percebida como um jogo de soma zero. A escolha de ter uma matriz que favoreça mais a distribuição ou a produção refletiria a preferência daqueles que possuem poder de barganha para determinar as regras do jogo. Contudo, segundo North, é possível transitar para um sistema de crenças em que a matriz institucional crie um conjunto de oportunidades em que se alcance um jogo do tipo win-win.

2 As organizações são grupos de indivíduos que se reúnem com o propósito de atingir objetivos comuns, podendo ser de diferentes tipos, como os corpos políticos (partidos, câmaras legislativas), econômicos (firmas, sindicatos), sociais (igrejas, clubes, associações) ou educacionais (universidades, escolas). Assim como as instituições, as organizações conferem uma estrutura para as interações entre os agentes individuais. Contudo, de acordo com clássica proposição de North, enquanto as instituições são as regras do jogo, as organizações são os jogadores (North, 1990, p. 4-5). 
Quarto: a chave para compreender as escolhas individuais são os modelos mentais dos indivíduos. Nos processos de mudança institucional, as escolhas refletem as informações que os agentes receberam e os modelos mentais que processam essas informações. Esses modelos, por sua vez, são frutos de diferentes aprendizados que conformam o conhecimento - técnico ou não - desses agentes. Assim, teorias da escolha devem especificar com cuidado os modelos subjetivos de tomada de decisões.

Quinto: economias de escopo, complementaridades e redes de externalidades, frutos de uma matriz institucional, implicam que a mudança será incremental e dependente da trajetória. Isso significa que, ao determinar os tipos de organizações que serão criados, as matrizes institucionais também determinam os tipos de relações de interdependência entre essas organizações e as condições para sua sobrevivência. O ponto fundamental é que não é fácil reverter trajetórias "do dia para a noite". Segundo o autor:

It is incremental because large-scale change will create too many opponents among existing organizations that will be harmed and therefore oppose such change. Revolutionary change will only occur in the case of gridlock among competing organizations which thwarts the ability of organizations to capture gains from trade. Path dependence will occur because the direction of the incremental institutional change will be broadly consistent with the existing institutional matrix (for the reasons described above) and will be governed by the kinds of knowledge and skills that the entrepreneurs and members of organizations have invested in (North, 2005, p. 62).

O importante é que, para North, o tempo exerce um papel crucial, de modo que uma tarefa central para os economistas seria conhecer a forma como as estruturas sociais evoluem. Ainda, pode-se afirmar que, em sua perspectiva, as conexões entre as estruturas podem mudar, pois aspectos culturais, políticos e econômicos estão em permanente interação. Portanto, quando se trata das fronteiras dos sistemas e subsistemas, na obra de North, elas são mutáveis. As estruturas sociais (institucionais, simbólicas e econômicas) evoluem, sendo esse o objeto central de sua investigação. Também, as relações e os limites entre estruturas e subsistemas não estão delineados a priori. Variam ao longo do tempo e entre os casos. Dessa maneira, observamos sistemas reais e complexos, que podem assumir formas diversas, as quais devem ser investigadas a partir de um olhar histórico.

Estruturas sociais estão imersas em outras estruturas sociais, sendo essa uma das características centrais dos sistemas abertos. A interação entre essas estruturas é significativa, dado o caráter permeável ou semipermeável de suas fronteiras. Essa é uma característica importante do marco analíti- 
co proposto por North. Como vimos no ponto anterior, as fronteiras dos sistemas possuem mutabilidade, por evoluírem ao longo do tempo e por ocorrer interações entre os subsistemas. Essas fronteiras são permeáveis e só podem ser apreendidas se observadas na sua relação com estruturas sociais mais amplas.

Nessa linha, pode-se afirmar que, em uma visão de longa duração, o processo de evolução das estruturas sociais implica processos de diferenciação que criam outras estruturas, as quais progressivamente passam a ter dinâmicas endógenas. Essas novas estruturas sociais herdam características das estruturas em que estavam imersas anteriormente, mas também criam sistemas simbólicos e formas institucionais próprias. Na obra de North, o estudo desses processos de herança e diferenciação é central para se criar teorias do desenvolvimento econômico, através de análises histórico-comparativas, quando observa, por exemplo, as especificidades das instituições latino-americanas.

\subsection{Produzindo conhecimento sobre sistemas abertos: o desafio de pensar a incerteza}

Quando se trata de sistemas abertos, podem existir variáveis ou relações entre variáveis que estão ocultas aos olhos do analista ou a classificação das variáveis entre endógenas e exógenas pode vir a ser alterada com o passar do tempo. Ainda, pode-se afirmar que, devido à possibilidade de existir variáveis ou relações desconhecidas, nem sempre essa classificação entre endógeno e exógeno é exaustiva. Por fim, mesmo que sejam conhecidas as variáveis e seus efeitos, o próprio sistema pode evoluir e desenvolver novas variáveis, com novas relações entre si.

Uma das implicações teóricas de se estudar sistemas abertos é que as conexões entre as estruturas e as fronteiras do sistema podem ser imperfeitamente conhecidas ou podem mudar com o tempo, tornando o conhecimento provisório (Chick; Dow, 2005; Dow, 2004). Tendo em vista essas características, é preciso construir teorias que tenham por objeto a mudança. Essas teorias devem conceber as interações entre agentes e estruturas de forma dinâmica.

Por essa razão, na obra aqui discutida, North não constrói sua teoria em cima de variáveis, no sentido matemático do termo. Seria mais apropriado 
dizer que North procura conjugar diferentes dimensões de análise em uma narrativa histórica, construída em cima de conceitos delineados no marco teórico institucionalista. Ao assumir a mudança econômica como seu objeto de análise, ele propõe que a condição para sua explicação é investigar as complexas relações existentes entre: mudança institucional, formação de estoques de conhecimento e mudanças demográficas.

Nessa tarefa, o acumulo de conhecimento sobre dinâmicas evolucionárias pelas Ciências Biológicas poderia ser utilizado pelos economistas (Hodgson; Knudsen, 2010). Contudo, salienta North, é preciso ter parcimônia, pois há uma limitação na aplicação de modelos evolucionários aos fenômenos humanos: nesses modelos não existem conceitos que deem conta da intencionalidade humana. Também, encontra-se o problema de não existir nos sistemas sociais algo semelhante aos genes. No mundo biológico, os genes são fatores fundamentais para explicar a reprodução dos seres vivos, bem como as variações ocorridas ao longo da evolução, em razão de processos de mutação. Nos fenômenos sociais não há uma partícula essencial que seja transformada e transmitida. Existem estruturas simbólicas, percepções e aprendizados que interagem de maneira complexa, conferindo consciência e intencionalidade aos processos. Nesse sentido, há limites para fazer analogias estreitas entre os processos socioeconômicos e os processos biológicos.

No mundo social, o próprio desenvolvimento dos sistemas é um processo de diferenciação estrutural marcado pela delimitação de fronteiras. A construção institucional, seja por ações deliberadas de criação de regras formais, seja pelo surgimento não intencional de normas e padrões de condutas informais, é a forma pelas quais essas fronteiras são delimitadas. Nesse sentido, a análise institucional possui em seu cerne a preocupação de criar métodos e teorias para observar como sistemas e estruturas sociais se conectam ou se desconectam. Por sua vez, isso implica conhecer os processos de aprendizados coletivos que estão na origem da mudança institucional.

Ao contrário do que poderia ser observado em suas obras pré-Nobel (Toyoshima, 1999), em sua obra de 2005, North se afasta consideravelmente do pensamento neoclássico. O autor é categórico ao afirmar que a teoria econômica tradicional não possui instrumentos para lidar com a incerteza que permeia um mundo em constante mudança, dado que é uma teoria estática, a qual não leva em conta a intencionalidade dos atores. A agência humana implica a permanente construção de novas formas ins- 
titucionais e de novos conhecimentos para lidar com a incerteza. Assim, ao incorporar a agência humana à teoria econômica, demanda-se um tipo de teoria complexa, que englobe a criação, a intencionalidade e o movimento. Dificilmente se conseguiria alguma forma de teoria universal e imutável que incorpore essas características dos sistemas econômicas. Ao assumir que os agentes sociais são dotados de intencionalidade e capacidade criativa, no máximo, seria possível alcançar teorias provisórias. Assim, North questiona: "If we are continually creating a new and novel world, how good is the theory we have developed from past experience to deal with this novel world?" (North, 2005, p. 13)?

Para ter uma noção das profundas implicações de incorporar a agência na teoria é preciso entender como a ideia de incerteza passa a ser central na análise de sistemas abertos. Segundo North, a noção de incerteza possui uma longa história nas Ciências Econômicas, sendo que a distinção entre risco e incerteza proposta por Frank Knight (1921) ainda hoje seria importante: risco seria aquela condição em que é possível atribuir uma distribuição de probabilidade ao fenômeno. A incerteza, por sua vez, não é mensurável, ela não é probabilística. Ao longo do século XX, a teoria ortodoxa teria abandonado o conceito de incerteza ou, quando assumiu o termo, fez significando risco ${ }^{3}$. North afirma que os economistas procederam como se a incerteza, no sentido de Knight, fosse algo não usual. Para os economistas daquele século, a grande maioria dos fenômenos poderia ser descrita através de distribuições probabilísticas e, dessa forma, a vantagem epistemológica estaria em desenvolver teorias matematicamente sofisticadas, simples e elegantes.

Contudo, afirma North, os economistas do século XX se equivocaram. Um olhar mais atento para a história faz perceber que a incerteza é a condição mais usual com que se deparam os seres humanos desde a pré-história até a era moderna. A incerteza é ubíqua, o mundo é não ergódigo e a ação humana pode ser entendida como um esforço para reduzir a incerteza do ambiente físico e sociocultural. Dessa forma, o conhecimento produzido pelo homem, em suas mais diversas facetas, incluindo as teorias científicas, seriam formas de lidar com a incerteza.

3 Isso fica explícito na seguinte passagem do famoso manual de microeconomia de Hal Varian: "A incerteza faz parte da vida. Arriscamo-nos todas as vezes que tomamos banho, atravessamos a rua ou fazemos um investimento. Há, porém, instituições financeiras, como os mercados de seguros e de ações, que podem aplacar pelo menos alguns desses riscos" (2015, p. 311). 
North estabelece a existência de diferentes graus de incertezas. Para cada grau, o homem desenvolve diferentes estratégias em busca de reduzi-las (North, 2005, p. 17): ( $\left.1^{\mathrm{a}}\right)$ dado determinado estoque de conhecimento, é possível produzir informações que reduzam a incerteza; $\left(2^{a}\right)$ dado determinado arranjo institucional (Institutional framework), é possível aumentar o estoque de conhecimento para reduzir a incerteza; ainda, $\left(3^{\mathrm{a}}\right)$ a incerteza pode ser reduzida, modificando os arranjos institucionais; $\left(4^{\mathrm{a}}\right)$ existe incerteza em face de novas situações que implica mudança nas crenças; $\left(5^{a}\right)$ por fim, há sempre a incerteza residual, que está na origem de crenças "não racionais".

As mais diversas mudanças podem ocorrer em direções não previsíveis. Essa é a essência de afirmar que há incerteza, pois deriva do fato de que não há como saber qual tipo de aprendizado os agentes terão no futuro. Bem como, pode haver uma distância significativa entre as intenções dos agentes e os resultados esperados na tomada de decisões. A todo tempo, as consequências não premeditadas das ações afetam os rumos das mudanças econômicas e institucionais. Portanto, não há garantias de que o conjunto de regras formais e normas informais que hoje são eficientes continuarão sendo amanhã.

Dessa forma, o problema central fica expresso quando North pontua que a maior dificuldade não está em criar mercados eficientes, mas em achar formas para que esses mercados permaneçam eficientes com o passar do tempo. A própria dinâmica de concorrência cria condições favoráveis para introdução de novas tecnologias, para a criação de novas regras informais ou para alterar as preferências de consumo. Essas novidades, por sua vez, podem colocar em xeque a eficiência dos mercados existentes. Isso pode ocorrer, por exemplo, através da criação de monopólios ou de assimetrias informacionais. Dessa forma, a estrutura institucional se tornaria antiquada, demandando reformulações.

É nesse sentido que o conceito de eficiência adaptativa passa a ser central, pois a performance do passado impõe a necessidade de buscar soluções para o presente, as quais, por sua vez, determinarão as trajetórias futuras. A ineficiência está na incapacidade de lidar com a novidade e, portanto, mais importante do que encontrar determinado receituário de instituições seria encontrar instituições com elevada capacidade de adaptação às realidades específicas de cada país. Isso implica desenvolver modelos mentais que façam leituras corretas do ambiente. Consequentemente, a 
própria ideia de um get institutions right passaria a ter um novo significado: "Getting it right through time means that we perceive correctly changes in the human environment, incorporate those perceptions in our belief system, and alter the institutions accordingly" (North, 2005, p. 116).

\section{Considerações finais}

Um dos grandes méritos de North é avançar na compreensão do papel cognitivo das instituições. Isso é feito ao colocar no centro de sua proposta o conceito de aprendizado. $O$ aprendizado é o elo entre as novas experiências e os modelos mentais previamente existentes. É a base da tomada de decisões, que relaciona a trajetória passada e as novidades do presente. Dessa forma, a mudança institucional tende a ser mais incremental do que revolucionária. A mudança econômica, por sua vez, deve ser analisada sob uma perspectiva de longa duração, observando os processos adaptativos de aprendizado que conformam as instituições e levam as sociedades a obter melhor ou pior desempenho em suas performances econômicas.

Ainda, seria possível afirmar que há sociedades que desenvolveram maior capacidade adaptativa, criando um arranjo institucional mais eficiente para lidar com a novidade e, especialmente, para garantir uma ordem social estável no que se refere às liberdades individuais e aos direitos de propriedade. Isso significa que essas sociedades desenvolveram formas mais eficazes de lidar com o problema da realização de trocas impessoais e da integração do conhecimento local dos agentes, potencializando as atividades produtivas.

Pode-se afirmar que as Ciências Sociais, em sentido amplo, fazem parte desse esforço de compreender o mundo para reduzir a incerteza. Não é à toa que nessas Ciências não se desenvolvam leis sobre o comportamento humano semelhante àquelas das Ciências da Natureza. Isso se deve justamente ao caráter não ergódigo do mundo, que implica mudança permanente, transformando constantemente a realidade e, consequentemente, o conhecimento. É justamente esse caráter não ergódigo do mundo que, frente à mudança e à novidade, condena, mais cedo ou mais tarde, qualquer conhecimento ao ostracismo.

Essa constatação poderia levar a uma atitude de descrença ou a uma percepção de inutilidade do fazer científico. Contudo, North acredita na 
ciência. Não é um cético. Pelo contrário, em sua visão, toda produção de conhecimento, científico ou não, é uma forma de lidar com essa incerteza. Segue disso sua percepção de que se quisermos criar uma teoria econômica mais útil faz-se necessário incorporar o pressuposto de que vivemos em um mundo não ergódigo. Em sua perspectiva, isso implica desenvolver o conhecimento que possuímos sobre as instituições humanas e sobre como estas se relacionam com a performance econômica.

Para tanto, o caminho seria integrar a análise institucional ao que já sabemos sobre crescimento econômico e elevação da produtividade. Nesse sentido, tornar-se-ia central investigar qual a relação entre mudança institucional e o aumento da quantidade e da qualidade do capital físico e humano. Ou seja, estaríamos investigando a relação entre instituições, demografia e estoque de conhecimento. Essa integração dependeria de avançar na discussão de três temas fundamentais: a existência de fricções econômicas, a incorporação da passagem do tempo e a compreensão da intencionalidade dos agentes. De toda forma, fica implícito em seu texto o reconhecimento de que seria ingênuo pensar que o avanço da economia institucional levaria ao desenvolvimento de uma estrutura de incentivos perfeita, que nos conferissem receitas para promoção do desenvolvimento econômico. Pelo contrário, o ponto central é humildemente incorporar em nossa consciência científica os limites do conhecimento que produzimos:

The key to useful institutional analysis is to take into account the imperfect nature of institutional incentive systems and build that understanding into the analytical framework. Only then will the institutional analysis make the essential contribution to political economic analysis that it is capable of making (North, 2005, p.67).

Essa postura é razoável, porém é permeada por uma tensão não desprezível. O processo de criação institucional, nessa perspectiva, é justamente explicado pela busca de lidar com a incerteza, em que se procura ter maior controle sobre o ambiente físico e humano. A própria racionalização científica sobre como esses processos ocorrem seria uma forma de lidar com essa incerteza. Assim, essa racionalização seria uma potência primordial da própria economia institucional: buscamos conhecer intimamente as instituições para melhorá-las e, assim, encontrar formas mais seguras de lidar com a escassez e com os problemas distributivos. Contudo, essa incerteza que objetivamos reduzir, por definição, estará sempre presente. Será eternamente uma sombra por trás do trabalho humano, incluindo aqui o laboro científico. Dessa forma, por mais que avançamos na racionalização 
em busca do controle do nosso ambiente, essa será uma tarefa permanentemente incompleta.

Então, é preciso conviver com essa tensão. Para tanto, necessita-se incorporar em nosso saber e em nossa prática de economistas a consciência de que as estruturas institucionais são e serão imperfeitas. Parece que esse é um dilema que os economistas do século XXI não poderão se dar ao luxo de ignorar. Um caminho importante é o de valorizar e interagir com os processos de aprendizados dos agentes econômicos e entender que eles são necessariamente diversos, frutos de experiências físicas e socioeconômicas específicas de cada sociedade. Isso vale para as Ciências Econômicas que, ao colocar essas questões, terá de assumir seu caráter plural e perceber que aí está sua força. Ainda, cabe pensar em instituições que potencializem a transformação desses aprendizados localizados em instituições e políticas públicas que atuem na resolução dos problemas emergentes. Nesse sentido, os economistas deveriam necessariamente ter uma postura democrática, concebendo a democracia com metainstituições para a criação de boas instituições (Rodrik, 2007). É sob essa fundamentação que se pode pautar uma ética eminentemente democrática e plural para a profissão.

\section{Referências}

ANGELI, E. A importância da história do pensamento econômico e do pluralismo metodológico em economia com base na perspectiva da Escola Austríaca. Nova Economia, v. 24, n. 1, p. 33-50, 2014.

AOKI, M. Understanding Douglass North in game-theoretic language. Structural Change and Economic Dynamics, v. 21, n. 2, p. 139-146, 2010.

AZEVEDO, B. Uma análise antropológica de Douglass North (1973-2009): indivíduo, racionalidade, cultura e instituições. Tese (Doutorado) - Instituto de Economia, Universidade Federal do Rio de Janeiro, Rio de Janeiro, 2015.

BIANCHI, A. M. Muitos métodos é o Método: a respeito do pluralismo. Revista de Economia Política, v. 12, n. 2 (46), p. 135-142, 1992.

CALDWELL, B. Beyond positivism: economic methodology in the twentieth century. London: Routledge, 1994.

CAMPOS, M. O processo de desenvolvimento econômico a partir de uma perspectiva institucionalista: elementos de uma abordagem heterodoxa. Tese (Doutorado) - Faculdade de Ciências Econômicas, Universidade Federal do Rio Grande do Sul, Porto Alegre, Brasil, 2016.

CHICK, V. On open systems. Revista de Economia Política, v. 13, n. 1, p. 3-16, 2004.

CHICK, V.; DOW, S. The meaning of open systems. Journal of Economic Methodology, v. 12, 
n. 3, p. 363-381, 2005

COLANDER, D.; HOLT, R.; ROSSER, J. The changing face of mainstream economics. Review of Political Economy, v. 16, n. 4, p. 485-499, 2004.

CONCEIÇÃO, O. O conceito de instituição nas modernas abordagens institucionalistas. Revista de Economia Contemporânea, v. 6, n. 2, p. 119-146, 2002.

CORCUFF, P. As novas sociologias: construções da realidade social. Sintra: Vral, 2001.

COSTA, E. A cultura como chave para a dependência da trajetória na teoria institucionalista de Douglas North. Nova Economia, v. 29, n. especial, p. 1.359-1.385, 2019.

DEQUECH, D. Neoclassical, mainstream, orthodox, and heterodox economics. Journal of Post Keynesian Economics, v. 30, n. 2, p. 279-302, 2007.

DOW, S. Structured pluralism. Journal of Economic Methodology, v. 11, n. 3, p. 275-290, 2004.

FEYERABEND, P. Contra o método. Rio de Janeiro: F. Alves, 1977.

FIANI, R. Estado e economia no institucionalismo de Douglass North. Revista de Economia Política, v. 23, n. 2, p. 135-149, 2003.

FULLBROOK, E. The crisis in Economics. The post-autistic economics movement: the first 600 days. Londres, 2003.

GALA, P. A retórica na economia institucional de Douglass North. Revista de Economia Política, v. 23, n. 2, p. 1-14, 2003.

GIDDENS, A. Dualidade da estrutura: agência e estrutura. Oeiras: Celta Editora, 2000.

HAYEK, F. The constitution of liberty. Chicago: University of Chicago Press, 1978.

HAYEK, F. The sensory order: an inquiry into the foundations of theoretical psychology. Chicago: University of Chicago Press, 1952.

HODGSON, G. Evolution and institutions: on evolutionary economics and the evolution of economics. Cheltenham: Edward Elgar, 1999.

HODGSON, G.; KNUDSEN, T. Darwin's conjecture: the search for general principles of social \& economic evolution. Chicago: Chicago University Press, 2010.

KNIGHT, F. Risk, uncertainty and profit. New York: Houghton Mifflin and Co, 1921.

LOPES, Herton. Instituições e crescimento econômico: os modelos teóricos de Thorstein Veblen e Douglass North. Revista de Economia Politica, v. 33, n. 4, p. 619-637, 2013.

NELSON, R.; WINTER, S. An evolutionary theory of economic change. Cambridge: Harvard University Press, 1982.

NORTH, D. Institutions, institutional change and economic performance. Cambridge: Cambridge University Press, 1990.

NORTH, D. Understanding the process of economic change. Princeton: Princeton University Press, 2005.

PAUlA, J. A.; CROCCO, M.; CERQUeIRA, H.; AlbUQUERQUE, E. Conhecimento e interesse em economia. Estudos Econômicos, São Paulo, v. 33, n. 3, p. 559-595, 2003.

PELIKAN, P. The formation of incentive mechanisms in different economic systems. IUI Working Papers, Stockholm, 1986. 
QUEIROZ-STEIN, G. Pluralismo e economia institucional: como fundamentar uma epistemologia plural? In: ENCONTRO DE ECONOMIA DA REGIÃO SUL, XXI., Curitiba, 2018.

RODRIK, D. One economics, many recipes: globalization, institutions and economic growth. New Jersey: Princeton University Press, 2007.

TOYOSHIMA, S. Instituições e desenvolvimento econômico: uma análise crítica das ideias de Douglass North. Estudos Econômicos, São Paulo, v. 29, n. 1, p. 95-112, 1999.

VARIAN, H. Microeconomia: uma abordagem moderna. Rio de Janeiro: Elsevier, 2015.

WALLIS, J. The New Economic History and beyond: the scholarship of Douglass C. North. Journal of Economic History, v. 76, n. 3, p. 937-947, 2016.

WILLIAMSON, O. The New Institutional Economics: taking stock, looking ahead. Journal of Economic Literature, v. 38, n. 3, p. 595-613, 2000.

\section{Sobre o autor}

Guilherme de Queiroz Stein-guiqstein@yahoo.com.br Institute für Politikwissenchaft, Westfälische Wilhelms-Universität Münster, Münster, Germany.

Programa de Pós-Graduação em Políticas Públicas, Universidade Federal do Rio Grande do Sul, Porto Alegre, RS, Brasil. ORCID: https://orcid.org/0000-0002-5970-7962.

O autor agradece a leitura e comentários feitos por Octávio Conceição, Rafael Spengler e Marcelo Campos. Agradece, também, aos editores e pareceristas anônimos pelas críticas e sugestões. Obviamente, qualquer equívoco é de responsabilidade exclusiva do autor.

\section{Sobre 0 artigo}

Recebido em 14 de maio de 2020. Aprovado em 13 de julho de 2020. 